$41(2) \mid 2012$

Varia

Bogotá, 9-11 de mayo de 2012

\title{
Coloquio Internacional: «La Constitución de 1812 en su Bicentenario»
}

Bogotá, 9-11 de mayo de 2012

\section{Georges Lomné}

\section{(2) OpenEdition}

\section{Journals}

Edición electrónica

URL: http://journals.openedition.org/bifea/676

DOI: 10.4000/bifea.676

ISSN: 2076-5827

\section{Editor}

Institut Français d'Études Andines

\section{Edición impresa}

Fecha de publicación: 1 julio 2012

Paginación: 299-303

ISSN: 0303-7495

\section{Referencia electrónica}

Georges Lomné, « Coloquio Internacional: «La Constitución de 1812 en su Bicentenario» », Bulletin de I'Institut français d'études andines [En línea], 41 (2) | 2012, Publicado el 01 diciembre 2012, consultado el 27 noviembre 2020. URL : http://journals.openedition.org/bifea/676 ; DOI : https://doi.org/10.4000/ bifea. 676

Les contenus du Bulletin de l'Institut français d'études andines sont mis à disposition selon les termes de la licence Creative Commons Attribution - Pas d'Utilisation Commerciale - Pas de Modification 4.0 International. 


\section{COLOQUIO INTERNACIONAL: «LA CONSTITUCIÓN DE 1812 EN SU BICENTENARIO»}

\section{Bogotá, 9-11 de mayo de 2012}

Este coloquio tuvo lugar en Bogotá, del 9 al 11 de mayo de 2012, en el auditorio de la Fundación Gilberto Alzate Avendaño. Fue convocado y coordinado por Heraclio Bonilla, en nombre de las Facultades de Derecho y Ciencias Humanas de la Universidad Nacional de Colombia, del Departamento de Historia de la misma universidad, del Instituto Colombiano de Antropología e Historia (ICANH), de la Alcaldía Mayor de Bogotá y del IFEA (UMIFRE 17, CNRS-MAE). Logró reunir a 20 conferencistas y comentaristas de 11 países.

Durante la sesión inaugural, Heraclio Bonilla (Universidad Nacional de Colombia) recalcó que este evento constituía la «última jornada de una larga saga con pretexto del Bicentenario». Mencionó muy en particular a los tres coloquios que 
la Universidad Nacional y el IFEA coorganizaron de manera estrecha: en agosto del 2008 sobre «Etnia, color y clase en los procesos de independencia de los países andinos» (Lomné, 2008; Bonilla, 2010); otro, de «carácter planetario», en noviembre de 2009, sobre la «cuestión colonial» (Bonilla, 2011) y, en abril 2011, sobre «América Latina y el mundo ante la guerra civil española y el mundo» (Lomné, 2011). Precisó el objetivo de ese coloquio, es decir analizar el impacto de «la Pepa», su praxis, en ambos hemisferios del imperio hispano. En rigor, una problemática mucho más difícil que la de atenerse meramente al contenido de la propia carta constitucional. En esta misma sesión el director del IFEA subrayó la continua colaboración del Instituto con la Universidad Nacional y mencionó también las diversas «cátedras de historia» coorganizadas con la Fundación Alzate desde el año 2009. Añadió, como lo hizo en otras ocasiones, que se trababa de pensar la Independencia y no de conmemorarla a secas.

Juan Marchena (Universidad Pablo de Olavide, Sevilla) abrió luego las sesiones del coloquio con una ponencia magistral «Cádiz en América. Retrato en sepia de un fracaso y una derrota». Después de una sentida hermenéutica del óleo de Goya «la verdad, el tiempo y la historia», interpretado nuevamente como una alegoría de la Constitución (González Troyano, 2012), Marchena recalcó la manera con la cual la carta gaditana alimentaba hoy en día en España un «relato mítico para consumo popular», que pretende celebrar la unidad nacional, haciendo caso omiso de la dimensión antiabsolutista que tuvo en la época. Empero, el interrogante esencial de Marchena versó sobre el fracaso de Cádiz en América, cuando en la Península misma sufrió más bien, a lo largo de dos siglos, una mera pero repetida «derrota». Adelantó que los liberales españoles no entendieron en 1810-1812 el mensaje de sus coetáneos americanos y procuraron dejar vigentes en América unos mecanismos del antiguo régimen con fines a impedir la independencia. Ignacio Castán (Los Reyes Católicos, Bogotá), disertó luego sobre «La constitución de Cádiz y sus influencias en el constitucionalismo latinoamericano». Recalcó de entrada que, a diferencia de Estados Unidos y Francia, los diputados habían legislado para todo un imperio. Luego, refutó parte de la argumentación de Isidro Vanegas sobre la imposible influencia de Cádiz en el primer constitucionalismo colombiano (Vanegas, 2012). Según Castán, los impresos gaditanos y los propios debates de las Cortes — que se plasmarían en el diario de sesiones - fueron conocidos en América desde 1810. Sin embargo, el ponente no descartó la radicalidad de la constitución de Tunja y tampoco negó la originalidad de varias cartas constitucionales neogranadinas. A continuación, evaluó la influencia de Cádiz sobre varias cartas americanas a partir de 1820.

La sesión de la tarde fue consagrada a la recepción de la constitución en el cono sur. Beatriz Bragoni (CONICET, Mendoza) presentó una ponencia titulada «Tras las huellas de Cádiz en el Río de la Plata revolucionario» durante la cual enfatizó el afán, tanto de San Martín como de Belgrano, de instalar una monarquía constitucional en Argentina. Por lo tanto, si el eco de Cádiz fue casi inexistente en el Río de la Plata, es menester estudiar las distintas propuestas monárquicas que fueron desarrolladas allí y suponían un protectorado, sea francés, inglés o portugués. Lucrecia Enríquez (Pontificia Universidad Católica de Chile, PUCC, 
Santiago) disertó luego sobre «Cádiz y la independencia chilena». Demostró que, al igual que en Argentina, la constitución gaditana jamás fue aplicada en Chile. Esto tuvo que ver con el proceso fundamentalmente local que se desarrolló durante la «Patria vieja» (1810-1814) y la violencia de la guerra civil entre la Junta Superior Gubernativa de Santiago y las numerosas provincias que permanecieron fieles al Rey. Uno debe acordarse que Chile siempre se pensó como un «reino con derechos propios». En resumidas cuentas, se podría hablar para Chile de una influencia de los debates de las Cortes de Cádiz mucho más que de la Constitución en sí. En la discusión que siguió, Manuel Chust recalcó el papel que desempeñó en Cortes uno de los dos diputados chilenos: Joaquín de Leiva.

El jueves 10 de mayo, el congreso se desplazó hacia el edificio de Posgrados de la Universidad Nacional de Colombia. Allí tuvieron lugar, en la mañana, las intervenciones de Sabrina Guerra (Universidad San Francisco de Quito) sobre «... Y la bobería se extiende a la señora del Pacífico: Guayaquil en el camino a la independencia»; Claudia Guarisco (Colegio Mexiquense) sobre «La constitución de 1812 y los indios de Lima y el valle de México» y Claudia Rosas (Pontificia Universidad Católica del Perú, PUCP) sobre «Los avatares del sueño liberal. La experiencia constitucional de 1812 en la cultura política peruana». Este ramillete de experiencias enseñó la gran diversidad de situaciones y experiencias vinculadas a la aplicación de la carta constitucional en el seno mismo de regiones fieles a la Corona. En la tarde, habló Eduardo Torres Cuevas (Universidad de la Habana) de «Cádiz y sus predecesoras americanas: conceptos y cambios hacia la modernidad». Siguieron las ponencias de Robinson Meza (Universidad de los Andes de Venezuela, Mérida): «La constitución de Cádiz y sus repercusiones en Venezuela» y de Ricardo Sánchez (Universidad Nacional de Colombia): «La evaluación de Carlos Marx sobre la Constitución de Cádiz de 1812».

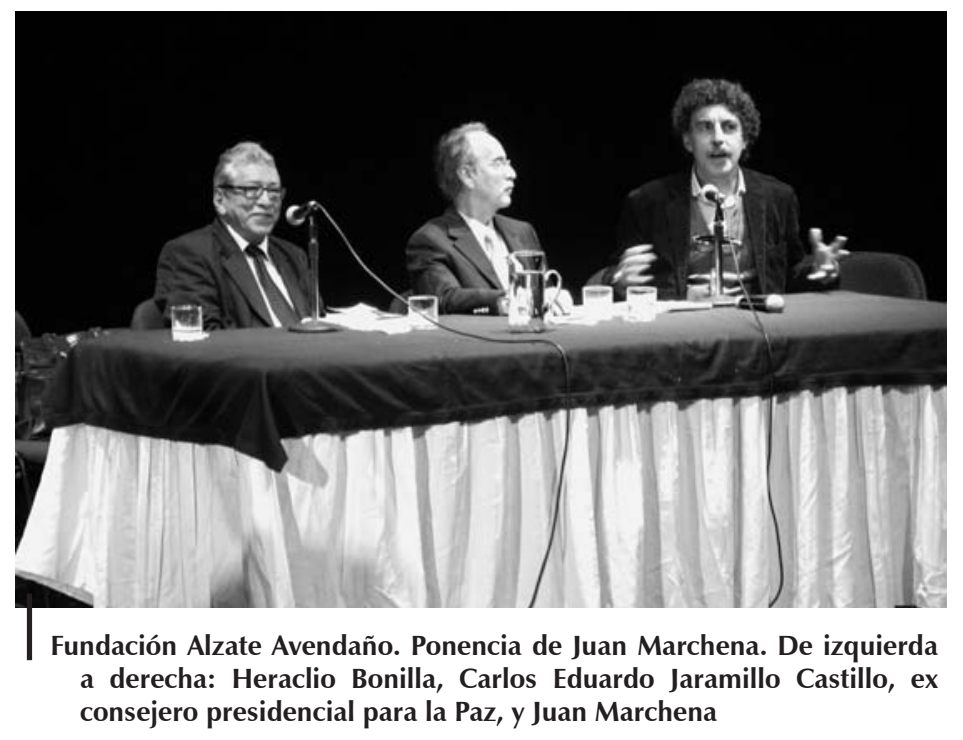


El viernes 11 de mayo, de regreso a la Fundación Alzate, el congreso abrió con una ponencia de mucha expectativa: «La constitución de Cádiz en la Nueva Granada, teoría y realidad, 1812-1821», que pronunció Víctor Manuel Uribe Urán (Florida International University). Basándose en los trabajos de Marcela Echeverri, el expositor recalcó la importancia que revistió la disminución del tributo indígena en la consolidación de la fidelidad de los pastusos hacia el Rey (Echeverri, 2011). El mismo fenómeno se observa en México, en 1810, y no sorprende entonces que los Patriotas hayan tomado similar medida en el Socorro (julio de 1810) o en Santafé (septiembre de 1810). En marzo de 1811, las Cortes de Cádiz eximieron a los indios del tributo y esto explicaría en gran parte la fidelidad de los indígenas del Magdalena, de Santa Marta y Riohacha. He aquí la importancia de disponer de una verdadera geopolítica del tributo en Colombia y de considerar cierto pragmatismo de los indígenas. El ponente lamentó también que no tuviéramos aún una visión de conjunto de la reorganización de los ayuntamientos en Colombia que sucedió en aquel entonces. En la discusión, Heraclio Bonilla recalcó que si disponíamos de una historia fiscal del tributo, hacía falta escribir todavía su historia económica y social: ¿Qué significa reducir el tributo cuando este era pagado en gran parte con gallinas y mantas? Polemizaron luego Víctor Uribe y Heraclio Bonilla sobre si los esclavos preferían la libertad o la seguridad material.

A continuación tuvo lugar la ponencia de Manuel Chust (Universidad Jaume I, Castellón) sobre: «De la revolución bi-hemisférica a la revolución española. 1812 versus 1837». El expositor, luego de una reflexión historiográfica sobre el legado gaditano, se interrogó sobre un obvio contraste: en 1812, se quiso fraguar un commonwealth hispano mientras que, en 1837, se quiso restringir el espacio nacional a la sola Península, devolviendo Cuba, Puerto Rico y Filipinas a la condición de meros protectorados. Un salto para atrás, ique propició el propio Agustín Argüelles! Dos continuidades aparecen, sin embargo, entre ambos momentos. La primera es la condena del federalismo, visto en 1812 y 1837, como disgregador de la nación y asociado a la forma republicana de gobierno. La segunda, es el rechazo de la idea que América sea parte integrante de la nación española: en 1812, era dominio personal del Rey; en 1837, sería dominio de la nación pero con el estatus de colonia. En definitiva, el ponente trató de demostrar que Argüelles sacrificó a América para que triunfara la revolución liberal en España. Por ende, vemos hasta qué punto la cuestión americana, durante el siglo XIX, no cesó de arbitrar los progresos de la democracia en la propia Península. Heraclio Bonilla (Universidad Nacional de Colombia) dictó la última ponencia del congreso, sobre «Abascal: la teoría y la praxis de la constitución de 1812». De entrada caracterizó de «anomalía», la ausencia de un movimiento juntero en el virreinato del Perú, y recalcó la figura de Abascal como «custodio más eficiente del orden colonial». Sin embargo, Bonilla se interrogó sobre el impacto que tuvo Cádiz en la rebelión de Huánuco y en formación de la Junta de Cuzco en 1814. Terminó afirmando de manera rotunda que en el caso peruano, la constitución no había servido sino de «coartada». 
Évènements

El Congreso concluyó en la tarde del 11 de mayo con una sesión de comentarios a cargo de Justo Cuño Bonito (Universidad Pablo de Olavide, Sevilla), Georges Lomné (IFEA), Medófilo Medina (Universidad Nacional de Colombia) y Víctor Manuel Moncayo (ex rector de la Universidad Nacional de Colombia).

\section{Referencias citadas}

BONILLA, H. (ed.), 2010 - Indios, negros y mestizos en la Independencia, 344 pp.; Bogotá: Universidad Nacional de Colombia y Planeta.

BONILLA, H. (ed.), 2011 - La cuestión colonial, 644 pp.; Bogotá: Universidad Nacional de Colombia.

ECHEVERRI, M., 2011 - Popular Royalists, Empire, and Politics in Southwestern New Granada, 1809-1819. Hispanic American Historical Review, 91 (2): 237-269.

GONZÁLEZ TROYANO, A., 2012 - La reinvención de un cuadro. Goya y la alegoría de la Constitución de 1812, 192 pp.; Madrid: Abada Editores.

LOMNÉ, 2008 - Reseña del evento: Seminario internacional: «Etnia, color y clase en los procesos de independencia de los países andinos». Bogotá, 27, 28 y 29 de agosto de 2008. Bulletin de l'Institut Français d'Études Andines, 37 (3): 569-572.

LOMNÉ, 2011 - Reseña del evento: Simposio: «América latina y el mundo ante la guerra civil española». Bogotá, 4-9 de abril de 2011. Bulletin de I'Institut Français d'Études Andines, 40 (1): 228-231.

VANEGAS, I., 2012 - El constitucionalismo fundacional, 190 pp.; Bogotá: Ediciones Plural. 